\title{
Risk profiles and pattern of antithrombotic use in patients with non-valvular atrial fibrillation in Thailand: a multicenter study
}

Rungroj Krittayaphong ${ }^{1 *} \mathbb{D}$, Arjbordin Winijkul ${ }^{1}$, Komsing Methavigul ${ }^{2}$, Wattana Wongtheptien ${ }^{3}$, Chaiyasith Wongvipaporn ${ }^{4}$, Treechada Wisaratapong ${ }^{5}$, Rapeephon Kunjara-Na-Ayudhya ${ }^{6}$, Smonporn Boonyaratvej ${ }^{7}$, Chulalak Komoltri ${ }^{8}$, Pontawee Kaewcomdee ${ }^{1}$, Ahthit Yindeengam ${ }^{1}$ and Piyamitr Sritara ${ }^{9}$ for the COOL-AF Investigators

\begin{abstract}
Background: Anticoagulation therapy is a standard treatment for stroke prevention in patients with non-valvular atrial fibrillation (NVAF) that have risk factors for stroke. However, anticoagulant increases the risk of bleeding, especially in Asians. We aimed to investigate the risk profiles and pattern of antithrombotic use in patients with NVAF in Thailand, and to study the reasons for not using warfarin in this patient population.
\end{abstract}

Methods: A nationwide multicenter registry of patients with NVAF was created that included data from 24 hospitals located across Thailand. Demographic data, atrial fibrillation-related data, comorbid conditions, use of antithrombotic drugs, and reasons for not using warfarin were collected. Data were recorded in a case record form and then transferred into a web-based system.

Results: A total of 3218 patients were included. Average age was $67.3 \pm 11.3$ years, and $58.2 \%$ were male. Average $\mathrm{CHADS}_{2}, \mathrm{CHA}_{2} \mathrm{DS}_{2}-\mathrm{VASc}$, and HAS-BLED score was $1.8 \pm 1.3,3.0 \pm 1.7$, and $1.5 \pm 1.0$, respectively. Antiplatelet was used in $26.5 \%$ of patients, whereas anticoagulant was used in $75.3 \%$. The main reasons for not using warfarin in those with $\mathrm{CHA}_{2} \mathrm{DS}_{2}-\mathrm{VASC} \geq 2$ included already taking antiplatelet (26.6\%), patient preference (23.1\%), and using non-vitamin $\mathrm{K}$ antagonist oral anticoagulants (NOACs) (22.7\%). Anticoagulant was used in $32.3 \%$ of $\mathrm{CHA}_{2} \mathrm{DS}_{2}$-VASc $0,56.8 \%$ of $\mathrm{CHA}_{2} \mathrm{DS}_{2}-\mathrm{VASC} 1$, and $81.6 \%$ of $\mathrm{CHA}_{2} \mathrm{DS}_{2}-\mathrm{VASC} \geq 2$. The use of NOACs increased from $1.9 \%$ in 2014 to $25.6 \%$ in 2017.

Conclusions: Anticoagulation therapy was prescribed in 75.3\% of patients with NVAF. Among those receiving anticoagulant, $90.9 \%$ used warfarin and $9.1 \%$ used NOACs. The use of NOACs increased over time.

Keywords: Risk profiles, Antithrombotics, Non-valvular atrial fibrillation, Thailand

\section{Background}

Non-valvular atrial fibrillation (NVAF) is a common cardiac arrhythmia in clinical practice with a prevalence of approximately $1-2 \%[1,2]$ which may be higher in patients with structural disease [3]. NVAF create a slow-flow situation within the atrium especially left atrial appendage leading to thrombus formation and thromboembolic event [1]. Current practice guidelines recommend the use of anticoagulant in patients with NVAF that have additional risk

\footnotetext{
* Correspondence: rungroj.kri@mahidol.ac.th

${ }^{1}$ Division of Cardiology, Department of Medicine, Faculty of Medicine Siriraj Hospital, Mahidol University, 2 Wanglang Road, Bangkoknoi, Bangkok 10700 Thailand

Full list of author information is available at the end of the article
}

factor(s) for stroke $[4,5]$. $\mathrm{CHA}_{2} \mathrm{DS}_{2}$ VASc score has been recommended as a risk stratification tool for predicting stroke in this group [4]. The annual risk of ischemic stroke in patients with non-valvular atrial fibrillation (NVAF) may be higher than $5 \%$ in patients with a high $\mathrm{CHA}_{2} \mathrm{DS}_{2-}$ VASc score [1]. Warfarin is associated with many types of food- and drug-related interactions, so international normalized ratio (INR) monitoring is needed [6, 7]. Although there are many non-vitamin $\mathrm{K}$ antagonist oral anticoagulants (NOAC), such as direct thrombin inhibitor and factor Xa inhibitors, warfarin is still widely used in Asian, and in low and middle income countries [8,9]. Although anticoagulation therapy can reduce ischemic stroke, it can also cause or contribute to major bleeding or intracerebral

(c) The Author(s). 2018 Open Access This article is distributed under the terms of the Creative Commons Attribution 4.0 International License (http://creativecommons.org/licenses/by/4.0/), which permits unrestricted use, distribution, and 
hemorrhage. Asian population was reported to have a higher risk of intracerebral hemorrhage, as a proportion of subtype of stroke, compared to Western population [2, 10]. Asian population also demonstrated a higher risk of warfarin-related intracerebral hemorrhage and bleeding-related complications $[11,12]$. For a variety of reasons, anticoagulant is prescribed in less than half of patients with $\mathrm{AF}$, including those in the intermediateand high-risk groups $[13,14]$. It is, therefore, important to study and understand the pattern of use of antithrombotic medication via the analysis of real-world data in this era.

Accordingly, the aim of this study was to investigate the risk profiles and pattern of antithrombotic use in patients with NVAF in Thailand, and to study the reasons for not using warfarin in this patient population.

\section{Methods}

\section{Study population and data}

NVAF patients were consecutively enrolled from 24 hospitals located all across Thailand. Thirteen of those centers are university hospitals, and ten are regional or general hospitals. The protocol for this study was approved by the institutional review boards (IRBs) of the Thailand Ministry of Public Health and IRB of each participating hospital namely Buddhachinaraj Hospital, Central Chest Institute of Thailand, Charoen Krung Pracha Rak Hospital, Chiangrai Prachanukroh Hospital, Chonburi Hospital, Chiang Mai Hospital, King Chulalongkorn Memorial Hospital, Naresuan University Hospital, Songklanakarind Hospital, Ramathibodi Hospital, Siriraj Hospital, Thammasat Hospital, Golden Jubilee Medical Center, Srinakarind Hospital, Lampang Hospital, Maharat Nakorn Ratchasima Hospital, Nakornping Hospital, Phramongkutklao Hospital, Police General Hospital, Prapokklao Hospital (Chanthaburi), Ratchaburi Hospital, Surat Thani Hospital, Surin Hospital, and Udonthani Hospital. All patients provided written informed consent prior to participation in this study. Patients aged $\geq 18$ years with atrial fibrillation diagnosed by standard ECG or ambulatory monitoring were eligible for inclusion. Patients having one or more of the following were excluded: 1) ischemic stroke within 3 months; 2) thrombocytopenia $(<100,000 / \mathrm{mm} 3)$, myeloproliferative disorders, hyperviscosity syndrome, or antiphospholipid syndrome; 3) prosthetic valve or valve repair; 4) rheumatic valve disease or significant valve disease; 5) atrial fibrillation from transient reversible cause (e.g., during respiratory tract infection or bronchospasm); 6) ongoing participation in a clinical trial; 7) life expectancy less than 3 years; 8 ) pregnancy; 9) inability to attend scheduled follow-up appointments; 10) refusal to join the study; and/ or, 11) current hospitalization or hospitalization within 1 month prior to inclusion in the study.
Baseline demographic and clinical data were collected and recorded. Patients were followed-up at 6, 12, 18, 24, 30, and 36 months. Data relating to cardiovascular events, blood pressure, heart rate, and medications were collected at each follow-up visit. Data from each patient was written on a case record form and keyed into a web-based data collection and management system. The following data were collected: 1) demographic information; 2) history of stroke and bleeding; 3) type and duration of atrial fibrillation; 4) component parameters of CHADS2 score, CHA2DS2VASc score for stroke risk, and HAS-BLED score for risk of bleeding; 5) history of medical and cardiovascular disease; 6) antithrombotic medication; 7) reason for not using warfarin in those not taking warfarin; 8) concomitant medications; 9) twelve-lead ECG; and, 10) current INR. Protocols were established and followed by the data management team and statisticians to ensure the integrity and quality of the data before final analysis. Random site monitoring was also regularly performed. Approximately $70 \%$ of sites were audited. Data were collected during the 2014 to 2017 study period.

\section{Statistical analysis}

Demographic and clinical data were interpreted using descriptive statistics. Continuous data are presented as mean \pm standard deviation, and categorical data are shown as number and percentage. All statistical analyses were performed using SPSS Statistics version 20 (SPSS, Inc., Chicago, IL, USA).

\section{Results}

A total of 3218 patients from 24 hospitals were included. Average age was $67.3 \pm 11.3$ years, and 1873 (58.2\%) were male. Baseline demographic data, clinical characteristics, and use of antithrombotic medications are shown in Table 1. Average $\mathrm{CHADS}_{2}, \mathrm{CHA}_{2} \mathrm{DS}_{2}$-VASc, and HAS-BLED score was $1.8 \pm 1.3,3.0 \pm 1.7$, and $1.5 \pm 1.0$, respectively. One-hundred and three patients (3.2\%) had history of radiofrequency ablation for atrial fibrillation. Among patients with coronary artery disease (CAD), 60 patients $(1.9 \%)$ had history of percutaneous coronary intervention (PCI) within 12 months.

Antiplatelet and anticoagulant was used in 854 (26.5\%) and $2422(75.3 \%)$ patients, respectively. Anticoagulant alone was used in 2125 (66.0\%) patients. Antiplatelet alone was prescribed in 557 (17.3\%) patients, and used in combination with anticoagulant in 297 (9.2\%) patients. Two hundred and thirty-nine $(9.2 \%)$ patients were taking no antithrombotic medications. Figure 1 describes the rate of use of antithrombotic agents in patients with different $\mathrm{CHA}_{2} \mathrm{DS}_{2}$-VASc and HAS-BLED scores. The rate of anticoagulant use increased in patients with a higher $\mathrm{CHA}_{2} \mathrm{DS}_{2}$-VASc score. Anticoagulant was used in $67(32.3 \%)$ patients with a $\mathrm{CHA}_{2} \mathrm{DS}_{2}$-VASc of 0 , in $238(56.8 \%)$ patients with a 
Table 1 Baseline characteristics of the study population and reasons for not using warfarin for those with CHA2DS2-VASC score $\geq 2$

\begin{tabular}{|c|c|}
\hline Variables & $N=3218$ \\
\hline Age (years), mean $\pm S D$ & $67.3 \pm 11.3$ \\
\hline Male gender, $n(\%)$ & $\begin{array}{l}1873 \\
(58.2 \%)\end{array}$ \\
\hline Time after diagnosis of atrial fibrillation (years), mean \pm SD & $3.4 \pm 4.4$ \\
\hline \multicolumn{2}{|l|}{ Type of atrial fibrillation, $n(\%)$} \\
\hline- New & $74(2.3 \%)$ \\
\hline - Paroxysmal & $\begin{array}{l}1001 \\
(31.1 \%)\end{array}$ \\
\hline - Persistent & $623(19.4 \%)$ \\
\hline - Permanent & $\begin{array}{l}1520 \\
(47.2 \%)\end{array}$ \\
\hline History of heart failure, $n(\%)$ & $875(27.2 \%)$ \\
\hline History of coronary artery disease, $n(\%)$ & $505(15.7 \%)$ \\
\hline Devices, $n(\%)$ & $330(10.3 \%)$ \\
\hline History of transient ischemic attack, $n(\%)$ & $121(3.8 \%)$ \\
\hline History of ischemic stroke, $n(\%)$ & $451(14.0 \%)$ \\
\hline Hypertension, $n(\%)$ & $\begin{array}{l}2183 \\
(67.8 \%)\end{array}$ \\
\hline Diabetes mellitus, $n(\%)$ & $777(24.1 \%)$ \\
\hline History of bleeding, $n$ (\%) & $308(9.6 \%)$ \\
\hline \multicolumn{2}{|l|}{ Antithrombotic medications, $n(\%)$} \\
\hline Antiplatelet & $854(26.5 \%)$ \\
\hline - Aspirin & $761(88.0 \%)$ \\
\hline - ADP/P2Y12 inhibitors & $191(22.2 \%)$ \\
\hline Anticoagulant & $\begin{array}{l}2422 \\
(75.3 \%)\end{array}$ \\
\hline - Warfarin & $\begin{array}{l}2202 \\
(90.9 \%)\end{array}$ \\
\hline - Direct thrombin inhibitor & $80(3.3 \%)$ \\
\hline - Factor Xa inhibitors & $140(5.8 \%)$ \\
\hline \multicolumn{2}{|l|}{$\mathrm{CHADS}_{2}$ score, $n(\%)$} \\
\hline-0 & 479 (14.9\%) \\
\hline-1 & $955(29.7 \%)$ \\
\hline-2 & $977(30.4 \%)$ \\
\hline-3 & $480(14.9 \%)$ \\
\hline-4 & $237(7.4 \%)$ \\
\hline-5 & $79(2.5 \%)$ \\
\hline-6 & $11(0.3)$ \\
\hline \multicolumn{2}{|l|}{ CHA2DS2-VASc score, $n(\%)$} \\
\hline-0 & 207 (6.4\%) \\
\hline-1 & 419 (13.0\%) \\
\hline-2 & $674(20.9 \%)$ \\
\hline-3 & $736(22.9 \%)$ \\
\hline-4 & $589(18.3 \%)$ \\
\hline-5 & $365(11.3 \%)$ \\
\hline
\end{tabular}

Table 1 Baseline characteristics of the study population and reasons for not using warfarin for those with CHA2DS2-VASC score $\geq 2$ (Continued)

\begin{tabular}{ll}
\hline Variables & $N=3218$ \\
\hline-6 & $163(5.1 \%)$ \\
-7 & $51(1.6 \%)$ \\
-8 & $13(0.4 \%)$ \\
-9 & $1(0 \%)$ \\
HAS-BLED score, $n$ (\%) & \\
- 0 & $458(14.2 \%)$ \\
- 1 & 1190 \\
& $(37.0 \%)$ \\
- 2 & 1067 \\
- 3 & $(33.2 \%)$ \\
- 4 & $403(12.5 \%)$ \\
- 5 & $84(2.6 \%)$ \\
- 6 & $15(0.5 \%)$ \\
Main reasons for not using warfarin, $n$ (\%) & $1(0 \%)$ \\
- Already taking anti-platelet drugs & $653(20.3 \%)$ \\
- Patient preference & $174(26.6 \%)$ \\
- Using NOACS & $151(23.1 \%)$ \\
- Bleeding risk & $148(22.7 \%)$ \\
- Physician preference & $90(13.8 \%)$ \\
- Fall risk & $89(13.6 \%)$ \\
- Warfarin compliance concern & $27(4.1 \%)$ \\
- Taking medication contra-indicated or cautioned for & \\
use with Warfarin & $22(3.4 \%)$ \\
\hline
\end{tabular}

$\mathrm{CHA}_{2} \mathrm{DS}_{2}$-VASc score of 1 , and in $2117(81.6 \%) \mathrm{pa}-$ tients with a $\mathrm{CHA}_{2} \mathrm{DS}_{2}$-VASc score of $\geq 2$ (Fig. 1a). Increased risk of bleeding, as reflected by a higher HAS-BLED score, did not influence a reduction in the use of anticoagulant (Fig. 1b). Among those who received anticoagulant, 2202 (90.9\%) used warfarin and $220(9.1 \%)$ used NOACs. When we analyzed the rate of NOAC use stratified by year of recruitment, an increase in the rate of NOAC use from $1.9 \%$ in 2014 to $25.6 \%$ in 2017 was observed (Additional file 1).

The reasons for not using warfarin in patients with a $\mathrm{CHA}_{2} \mathrm{DS}_{2}$-VASc score $\geq 2$ that were not taking warfarin are shown in Table 1 . The main reasons included already taking antiplatelet in 174 (26.6\%) patients, patient preference not to take warfarin in 151 (23.1\%), and current use of NOACs in 148 (22.7\%).

\section{Discussion}

In this study of 2014-2017 data from a multicenter registry in Thailand for patients with NVAF, we found a rate of anticoagulant use of $75.3 \%$. However, only $41.8 \%$ 


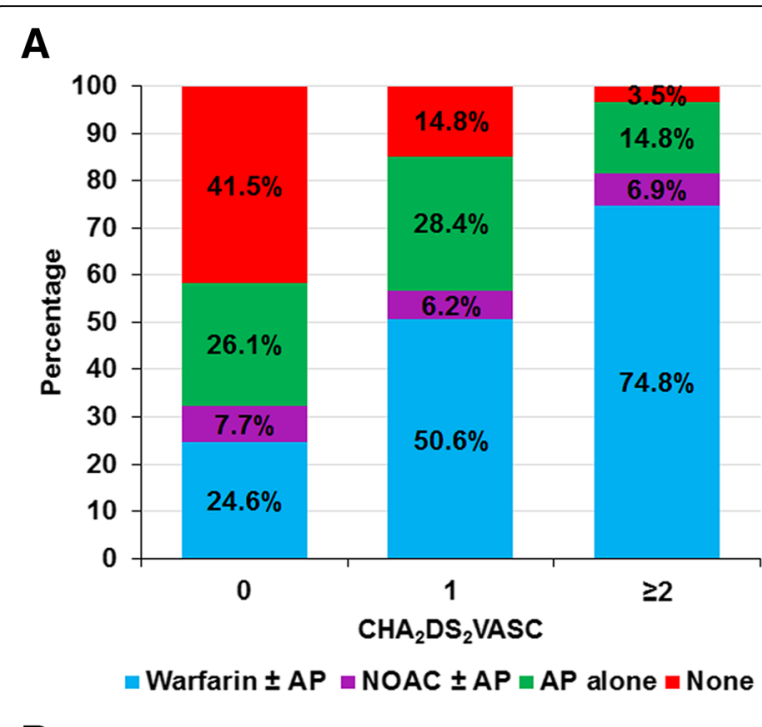

B

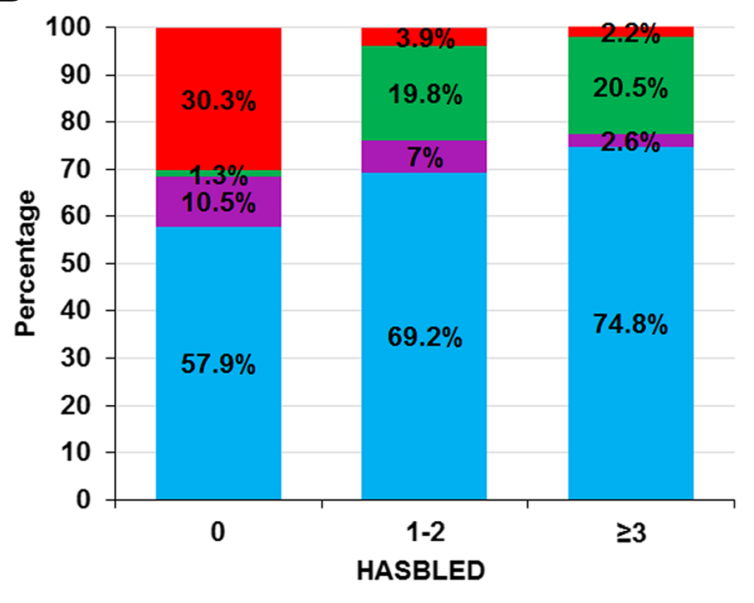

-Warfarin \pm AP $\approx$ NOAC \pm AP $\backsim A P$ alone $\square$ None

Fig. 1 Use of antithrombotic treatment stratified by $\mathrm{CHA}_{2} \mathrm{DS}_{2}-\mathrm{VASC}$ score (a) and HAS-BLED (b) score. (Abbreviations: AP, antiplatelet; NOAC, non-vitamin $\mathrm{K}$ antagonist oral anticoagulant)

of NVAF patients on warfarin had an INR within the 23 therapeutic range.

The baseline profiles of our study population are similar to the profiles described in previous reports [15-18]. The higher rate of anticoagulant use of $75.3 \%$ in this study compared to previous publications $[13,19]$ may be due to the implementation of clinical practice guidelines for the management of patients with NVAF [5, 20, 21].

GARFIELD AF enrolled patients with newly diagnosed NVAF starting with Cohort 1 in 2010-2011 [22, 23]. Only $56 \%$ of patients in Cohort 1 received anticoagulant. The rate of anticoagulant use markedly increased in 2015 [24]. Asian population in the GARFIELD registry had a lower percentage of anticoagulant use when compared to other regions of the world (38\% vs. 53\%) [25].
Data from the initial phase of GLORIA AF during 2011 to 2013 indicated that the rate of anticoagulant use was only $33 \%$ [26]. Anticoagulant use increased to $80 \%$ during phase 2, which enrolled patients until 2014. There was a difference in the rate of anticoagulant use ( $90 \%$ vs. $52 \%$ ) and NOAC use (52\% vs. $28 \%$ ) between Western and Asian populations in GLORIA phase 2 [27]. Anticoagulant use in the present study was greater than the rate among Asian population in GLORIA phase 2, but the use of NOACs in our study was lower. In addition to China - Japan, Korea, Taiwan, and Singapore participated in GLORIA - all of which are high income Asian countries. In many other low to middle income countries like Thailand, governments limit the use of and reimbursement for new and expensive drugs. Regardless, our data shows an increase in the use of NOACs over time by year of enrollment.

Other registries in Western population include the ORBIT AF registry [16], which was conducted in the US during 2010 to 2011, and EORP AF, which was conducted in European countries [18]. Both studies confirmed a high rate of anticoagulant use ( $76 \%$ and $80 \%$, respectively). However, among very low-risk patients (i.e., $\mathrm{CHA}_{2} \mathrm{DS}_{2^{--}}$ VASc 0 ), the rate of anticoagulant use from previous reports is $38-56 \%[16,18,22]$, which is close to consistent with the $32 \%$ rate of use found in the present study. Some patients may be on anticoagulation for reasons that include pre-cardioversion and/or post-cardioversion anticoagulation therapy, or they might have some degree of left ventricular systolic dysfunction, but they did not fit the criteria for $\mathrm{CHA}_{2} \mathrm{DS}_{2}$-VASc scor. This data also suggests that physicians fear stroke, even in patients at very low risk. In very low-risk patients, especially when young, an anatomical approach should be considered to delay relapse and to maintain sinus rhythm in order to reduce the need for OAC [28].

We herewith propose some possible explanations regarding why we observed a relatively high rate of anticoagulant use in this study. First, our registry is more recent. Second, almost all of the patients included in this study were managed by cardiologists, which may provide better care for patients with NVAF than non-cardiologists [29]. Third, most of the centers that participated in this registry are tertiary care hospitals.

Reasons for not using warfarin in this study included taking antiplatelet in $26.6 \%$, patient preference (or patient prefers not to take anticoagulants) in $23.1 \%$, and current use of NOACs in $22.7 \%$. The main reason for not using warfarin from the GARFIELD registry [22] was physician's choice (48.3\%). Already taking antiplatelet is the reason for not using warfarin in only $7.2 \%$ of patients in the GARFIELD registry. This rate is much lower than the rate from our study, which indicates that the use of antiplatelet remains more common among Asian population. 
This study has some mentionable limitations. First, our study population was enrolled mainly from university hospitals or large regional hospitals, which limits the generalizability. Second, we were unable to correlate the findings of this study with clinical outcomes since the 3-year follow-up data acquisition process is not yet completed.

\section{Conclusion}

Antithrombotic drugs were prescribed in $75.3 \%$ of patients with NVAF. Among those who received anticoagulant, $90.9 \%$ used warfarin and $9.1 \%$ used NOACs.

\section{Additional file}

Additional file 1: Rate of NOAC use stratified by year of recruitment. Rate of NOAC use increases as the year of enrollment more recent. (PDF $69 \mathrm{~kb}$ )

\section{Abbreviations}

INR: International normalized ratio; IRB: Institutional review board; NOAC: Non-vitamin K antagonist oral anticoagulant; NVAF: Non-valvular atrial fibrillation; TIA: Transient ischemic attack

\section{Acknowledgements}

The authors gratefully acknowledge Wipaporn Wangworatrakul, Olaree Chaiphet and Wilasinee Phromawan for data management, and all investigators and nurse coordinators for their assistance with patient enrollment and their commitment to maintaining a high level of data quality. The authors would also like to thank all of the patients that agreed to participate in this study.

Investigators list

Buddhachinaraj Hospital: Tomorn Thongsri, MD; Central Chest Institute of Thailand: Kriengkrai Hengrussamee, MD; Charoen Krung Pracha Rak Hospital: Pattraporn Srirattana, MD; Chiangrai Prachanukroh Hospital: Wattana Wongtheptien, MD; Chonburi Hospital: Pornchai Ngamjanyaporn, MD; Faculty of Medicine, Chiang Mai University: Arintaya Phrommintikul, MD; Faculty of Medicine, Chulalongkorn University: Smonporn Boonyaratavej, MD; Faculty of Medicine, Naresuan University: Pongpun Jittham, MD; Faculty of Medicine, Prince of Songkla University: Treechada Wisaratapong, MD; Faculty of Medicine Ramathibodi Hospital, Mahidol University: Sirin Apiyasawat, MD; Faculty of Medicine Siriraj Hospital, Mahidol University: Arjbordin Winijkul, MD, Rungroj Krittayaphong, MD; Faculty of Medicine, Thammasat University (Rangsit Campus): Roj Rojjarekampai, MD; Faculty of Medicine Vajira Hospital, Navamindradhiraj University: Kulyot Jongpiputvanich, MD; Golden Jubilee Medical Center: Somchai Dutsadeevettakul, MD; Srinakarind Hospital, Faculty of Medicine, Khon Kaen University: Chaiyasith Wongvipaporn, MD; Lampang Hospital: Thanita Boonyapiphat, MD; Maharat Nakorn Ratchasima Hospital: Weerapan Wiwatworapan, MD; Nakornping Hospital: Khanchai Siriwattana, MD; Pattani Hospital: Eakarnantha Arnanththanitha, MD; Photharam Hospital: Watchara Konkaew, MD; Phramongkutklao College of Medicine: Thoranis Chantrarat, MD; Police General Hospital: Kasem Ratanasumawong, MD; Prapokklao Hospital (Chanthaburi): Wiwat Kanjanarutjawiwat, MD; Queen Savang Vadhana Memorial Hospital: Sakaorat Kornbongkotmas; MD; Ratchaburi Hospital: Thanasak Patmuk, MD; Sapphasitthiprasong Hospital: Praprut Thanakitcharu, MD; Surat Thani Hospital: Suchart Arunsiriwattana, MD; Surin Hospital: Thaworn Choochunklin; MD; Udonthani Hospital: Sumon Tangsuntornwiwat, MD.

\section{Funding}

This study was funded by the Health System Research Institute (HSRI) (59-053), the Heart Association of Thailand under the Royal Patronage of H.M. the King, and the Royal College of Physicians of Thailand. None of the aforementioned funding sources influenced any aspect of this study or the authors' decision to submit this manuscript for publication.

\section{Availability of data and materials}

The dataset that was used to support the conclusion of this study is included within the manuscript. Any other additional data will be made available upon request.

\section{Authors' contributions}

RK - concept and design, data acquisition, interpretation of data, manuscript preparation, manuscript revision, and manuscript review; AW, KM, RKN, SB, PS - concept and design, data acquisition, interpretation of data, manuscript revision, and manuscript review; WW, CW, TW - data acquisition, manuscript revision, and manuscript review; CK - data interpretation, manuscript revision, and manuscript review; PK, AY - concept and design, data acquisition, manuscript revision, and manuscript review. All authors read and approved the final manuscript, and approved the submission of this manuscript for journal publication.

\section{Ethics approval and consent to participate}

The study protocol was approved by the institutional review boards of all participating hospitals. Written informed consent was obtained from all included patients prior to participation.

\section{Consent for publication}

Not applicable.

\section{Competing interests}

The authors declare that they have no competing interest.

\section{Publisher's Note}

Springer Nature remains neutral with regard to jurisdictional claims in published maps and institutional affiliations.

\section{Author details}

'Division of Cardiology, Department of Medicine, Faculty of Medicine Siriraj Hospital, Mahidol University, 2 Wanglang Road, Bangkoknoi, Bangkok 10700, Thailand. ${ }^{2}$ Department of Cardiology, Central Chest Institute of Thailand, Nonthaburi, Thailand. ${ }^{3}$ Chiangrai Prachanukroh Hospital, Chiang Rai, Thailand. ${ }^{4}$ Srinakarind Hospital, Faculty of Medicine, Khon Kaen University, Khon Kaen, Thailand. ${ }^{5}$ Faculty of Medicine, Prince of Songkla University, Songkla, Thailand. ${ }^{6}$ Vichaiyut Hospital and Medical Center, Bangkok, Thailand. ${ }^{7}$ Faculty of Medicine, Chulalongkorn University, Bangkok, Thailand. ${ }^{8}$ Department of Research Promotion, Faculty of Medicine Siriraj Hospital, Mahidol University, Bangkok, Thailand. ${ }^{9}$ Faculty of Medicine Ramathibodi Hospital, Mahidol University, Bangkok, Thailand.

Received: 7 May 2018 Accepted: 20 August 2018

Published online: 25 August 2018

\section{References}

1. Lip GYH, Brechin CM, Lane DA. The global burden of atrial fibrillation and stroke: a systematic review of the epidemiology of atrial fibrillation in regions outside North America and Europe. Chest. 2012;142(6):1489-98.

2. Tse HF, Wang YJ, Ahmed Ai-Abdullah M, Pizarro-Borromeo AB, Chiang CE, Krittayaphong R, Singh B, Vora A, Wang CX, Zubaid M, et al. Stroke prevention in atrial fibrillation--an Asian stroke perspective. Heart Rhythm. 2013;10(7):1082-8.

3. Anselmino M, Ferraris F, Cerrato N, Barbero U, Scaglione M, Gaita F. Left persistent superior vena cava and paroxysmal atrial fibrillation: the role of selective radio-frequency transcatheter ablation. J Cardiovasc Med (Hagerstown). 2014;15(8):647-52.

4. Kirchhof P, Benussi S, Kotecha D, Ahlsson A, Atar D, Casadei B, Castella M, Diener HC, Heidbuchel H, Hendriks J, et al. 2016 ESC guidelines for the management of atrial fibrillation developed in collaboration with EACTS. Eur Heart J. 2016:37(38):2893-962.

5. Chiang CE, Okumura K, Zhang S, Chao TF, Siu CW, Wei Lim T, Saxena A, Takahashi Y, Siong Teo W. 2017 consensus of the Asia Pacific Heart Rhythm Society on stroke prevention in atrial fibrillation. J Arrhythm. 2017;33(4):345-67.

6. Holbrook AM, Pereira JA, Labiris R, McDonald H, Douketis JD, Crowther M, Wells PS. Systematic overview of warfarin and its drug and food interactions. Arch Intern Med. 2005:165(10):1095-106.

7. Connolly SJ, Pogue J, Eikelboom J, Flaker G, Commerford P, Franzosi MG, Healey JS, Yusuf S, Investigators AW. Benefit of oral anticoagulant over antiplatelet therapy in atrial fibrillation depends on the quality of international normalized ratio control achieved by centers and countries as measured by time in therapeutic range. Circulation. 2008;118(20):2029-37. 
8. Guo Y, Wang H, Tian Y, Wang Y, Lip GYH. Time trends of aspirin and warfarin use on stroke and bleeding events in Chinese patients with newonset atrial fibrillation. Chest. 2015;148(1):62-72.

9. Jedsadayanmata A. Patterns and adherence to guidelines of antithrombotic therapy in Thai patients with nonvalvular atrial fibrillation. J Med Assoc Thail. 2013;96(1):91-8.

10. Chau PH, Woo J, Goggins WB, Tse YK, Chan KC, Lo SV, Ho SC. Trends in stroke incidence in Hong Kong differ by stroke subtype. Cerebrovasc Dis. 2011;31(2):138-46.

11. Shen AY, Yao JF, Brar SS, Jorgensen MB, Chen W. Racial/ethnic differences in the risk of intracranial hemorrhage among patients with atrial fibrillation. J Am Coll Cardiol. 2007:50(4):309-15.

12. Chiang CE, Wang KL, Lip GYH. Stroke prevention in atrial fibrillation: an Asian perspective. Thromb Haemost. 2014;111(5):789-97.

13. Waldo AL, Becker RC, Tapson VF, Colgan KJ, Committee NS. Hospitalized patients with atrial fibrillation and a high risk of stroke are not being provided with adequate anticoagulation. J Am Coll Cardiol. 2005;46(9):1729-36.

14. Yang X, Li Z, Zhao X, Wang C, Liu L, Wang C, Pan Y, Li H, Wang D, Hart RG, et al. Use of warfarin at discharge among acute ischemic stroke patients with Nonvalvular atrial fibrillation in China. Stroke. 2016:47(2):464-70.

15. Chiang CE, Wang KL, Lin SJ. Asian strategy for stroke prevention in atrial fibrillation. Europace. 2015;17(Suppl 2):ii31-9.

16. Cullen MW, Kim S, Piccini JP Sr, Ansell JE, Fonarow GC, Hylek EM, Singer DE, Mahaffey KW, Kowey PR, Thomas L, et al. Risks and benefits of anticoagulation in atrial fibrillation: insights from the outcomes registry for better informed treatment of atrial fibrillation (ORBIT-AF) registry. Circ Cardiovasc Qual Outcomes. 2013;6(4):461-9.

17. Oldgren J, Healey JS, Ezekowitz M, Commerford P, Avezum A, Pais P, Zhu J, Jansky $P$, Sigamani A, Morillo CA, et al. Variations in cause and management of atrial fibrillation in a prospective registry of 15,400 emergency department patients in 46 countries: the RE-LY atrial fibrillation registry. Circulation. 2014;129(15):1568-76.

18. Lip GY, Laroche C, Dan GA, Santini M, Kalarus Z, Rasmussen LH, Oliveira MM Mairesse G, Crijns HJ, Simantirakis E, et al. A prospective survey in European Society of Cardiology member countries of atrial fibrillation management: baseline results of EURObservational research Programme atrial fibrillation (EORP-AF) pilot general registry. Europace. 2014;16(3):308-19.

19. Gage BF, Boechler M, Doggette AL, Fortune G, Flaker GC, Rich MW, Radford MJ. Adverse outcomes and predictors of underuse of antithrombotic therapy in medicare beneficiaries with chronic atrial fibrillation. Stroke. 2000; 31(4):822-7.

20. Guidelines for Pharmacotherapy of Atrial Fibrillation (JCS 2013). Circ J 2014, 78(8):1997-2021.

21. Chiang CE, Wu TJ, Ueng KC, Chao TF, Chang KC, Wang CC, Lin YJ, Yin WH Kuo JY, Lin WS, et al. 2016 guidelines of the Taiwan Heart Rhythm Society and the Taiwan Society of Cardiology for the management of atrial fibrillation. J Formos Med Assoc. 2016;115(11):893-952.

22. Kakkar AK, Mueller I, Bassand JP, Fitzmaurice DA, Goldhaber SZ, Goto S, Haas S, Hacke W, Lip GY, Mantovani LG, et al. Risk profiles and antithrombotic treatment of patients newly diagnosed with atrial fibrillation at risk of stroke: perspectives from the international, observational, prospective GARFIELD registry. PLoS One. 2013;8(5):e63479.

23. Fox KAA, Gersh BJ, Traore S, John Camm A, Kayani G, Krogh A, Shweta S, Kakkar AK, Investigators G-A. Evolving quality standards for large-scale registries: the GARFIELD-AF experience. Eur Heart J Qual Care Clin Outcomes. 2017;3(2):114-22.

24. Camm AJ, Accetta G, Ambrosio G, Atar D, Bassand JP, Berge E, Cools F, Fitzmaurice DA, Goldhaber SZ, Goto S, et al. Evolving antithrombotic treatment patterns for patients with newly diagnosed atrial fibrillation. Heart. 2017;103(4):307-14.

25. Oh S, Goto S, Accetta G, Angchaisuksiri P, Camm AJ, Cools F, Haas S, Kayani $G$, Koretsune Y, Lim TW, et al. Vitamin K antagonist control in patients with atrial fibrillation in Asia compared with other regions of the world: realworld data from the GARFIELD-AF registry. Int J Cardiol. 2016;223:543-7.

26. Huisman MV, Ma CS, Diener HC, Dubner SJ, Halperin JL, Rothman KJ, Teutsch C, Schoof N, Kleine E, Bartels DB, et al. Antithrombotic therapy use in patients with atrial fibrillation before the era of non-vitamin $\mathrm{K}$ antagonist oral anticoagulants: the global registry on long-term oral antithrombotic treatment in patients with atrial fibrillation (GLORIA-AF) phase I cohort. Europace. 2016;18(9):1308-18.
27. Huisman MV, Rothman KJ, Paquette M, Teutsch C, Diener HC, Dubner SJ, Halperin JL, Ma CS, Zint K, Elsaesser A, et al. The changing landscape for stroke prevention in AF: findings from the GLORIA-AF registry phase 2. J Am Coll Cardiol. 2017:69(7):777-85.

28. Barbero U, Ho SY. Anatomy of the atria : A road map to the left atrial appendage. Herzschrittmacherther Elektrophysiol. 2017;28(4):347-54.

29. Turakhia MP, Hoang DD, Xu X, Frayne S, Schmitt S, Yang F, Phibbs CS, Than $C T$, Wang PJ, Heidenreich PA. Differences and trends in stroke prevention anticoagulation in primary care vs cardiology specialty management of new atrial fibrillation: the retrospective evaluation and assessment of therapies in AF (TREAT-AF) study. Am Heart J. 2013;165(1):93-101. e101
Ready to submit your research? Choose BMC and benefit from:

- fast, convenient online submission

- thorough peer review by experienced researchers in your field

- rapid publication on acceptance

- support for research data, including large and complex data types

- gold Open Access which fosters wider collaboration and increased citations

- maximum visibility for your research: over $100 \mathrm{M}$ website views per year

At BMC, research is always in progress.

Learn more biomedcentral.com/submissions 